\title{
Isolated Submental Lymphadenopathy
}

Micah Gibson ${ }^{1}$, Vikas Gupta ${ }^{1}$, Hunter Nolen ${ }^{1}$ and Lynnette J Mazur ${ }^{1 *}$

University of Lancashire, Lancashire, United Kingdom.

*Corresponding Author: Lynnette J Mazur, University of Lancashire, Lancashire, United Kingdom.

Received date: July 02, 2021: Accepted date: Augusł 04, 2021: Published date: Augusł 28, 2021

Citation: Micah Gibson, Vikas Gupta, Hunter Nolen and Lynnette J Mazur (2021) Isolated Submental Lymphadenopathy. J. of Clin Case Rep and Stu 2(5); DOI: 10.31579/2690-8808/084

Copyright: (C) 2021 Lynnette J Mazur. This is an open access article distributed under the Creative Commons Attribution License, which permits unrestricted use, distribution, and reproduction in any medium, provided the original work is properly cited.

\begin{abstract}
A 5 year old female presented to clinic with a lump under her chin. She had a similar lump two months ago but the parents stated that it spontaneously resolved in a few days. There was no history of fever and there were no pets. Her past medical history was significant for epilepsy which was controlled with zonisamide. On physical examination a $3 \times 2.5 \mathrm{~cm}$, soft, nontender, nonmobile submental mass and perioral dermatitis were noted. (Figures 1,2) A complete blood count (CBC) and an ultrasound (US) were ordered.

Keywords: lymphadenopathy; acute inflammation; anticonvulsants
\end{abstract}

\section{Introduction}

Masses in the head and neck region have several causes but most cases in children are infectious [1]. (Figure 3) Local staphylococcal and streptococcal infections can present with submandibular lymphadenopathy; however, children are usually febrile and the nodes are usually tender. Viral pathogens, adenovirus and RSV, and cat scratch disease secondary to Bartonella henselae and nontuberculosis mycobacteria are also possible [2, 3, 4].

Thyroglossal duct cysts present as midline neck masses and occur in approximately $7 \%$ of the population [5]. During embryologic development the thyroid gland migrates from the base of the tongue to the neck. If the remaining duct fails to obliterate, cysts can occur. Because they are near the hyoid bone, elevation can be noted with swallowing and tongue protrusion [5].

\section{Case Report}

Lymphadenopathy secondary to malignancy lacks signs of acute inflammation such as erythema and warmth and patients can have constitutional symptoms such as weight loss, fever, and fatigue [6]. Supraclavicular or posterior cervical adenopathy are particularly worrisome [7, 8]. Cervical adenopathy in patients less than 6 years old is associated with neuroblastoma and leukemia whereas in patients older than 6 years it is more commonly associated with Hodgkin's lymphoma, non-Hodgkin's lymphoma and rhabdomyosarcoma [7,9].
Anticonvulsants can cause lymphadenopathy or a Drug Induced Hypersensitivity Reaction (DIHS) [10]. Our patient was taking Zonisamide but lacked other features of DIHS such as generalized lymphadenopathy, fever, and eosinophilia.

Most children with cervical lymphadenopathy do not require laboratory testing; a two to four week period of observation is reasonable for nodes that are small, soft, and mobile [9]. The American College of Radiology recommends US for initial imaging for afebrile children with a neck mass $[1,10]$. US can differentiate between lymph nodes and other etiologies. When systemic illness is suspected, a CBC may be helpful [10].

If lymphadenopathy fails to regress after 4-6 weeks, a biopsy may be indicated $[9,11]$. Indications for excisional biopsy include an enlarged supraclavicular node, a node larger than $3 \mathrm{~cm}$, nodes in pediatric patients with history of malignancy, and constitutional findings [9]. Fine needle aspiration is useful in the management of cervical lymphadenopathy, however, it is less helpful in children due to a different differential diagnosis in this patient population [6].

In conclusion, when our patient returned two days later, the mass had reduced in size by almost $50 \%$. Her $\mathrm{CBC}$ was normal and the US revealed a submental node measuring $1.2 \times 1 \times 0.5 \mathrm{~cm}$. Therefore, we suspected that lip-licker's dermatitis was the most likely etiology [12]. Lip moisturizers were recommended along with avoidance of her lip licking habit $[11,12]$. 


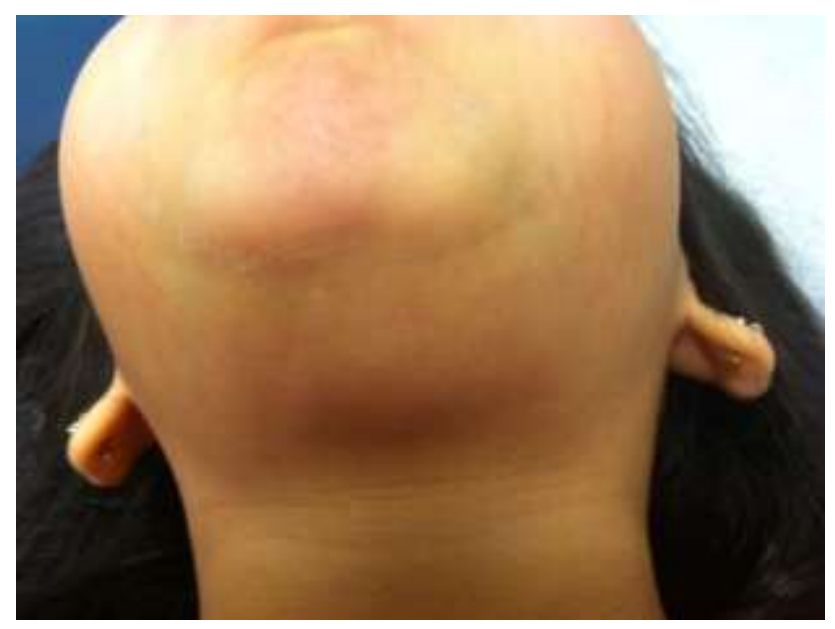

Figure 1: Inferior view of submental mass measuring $3 \times 2.5 \mathrm{~cm}$

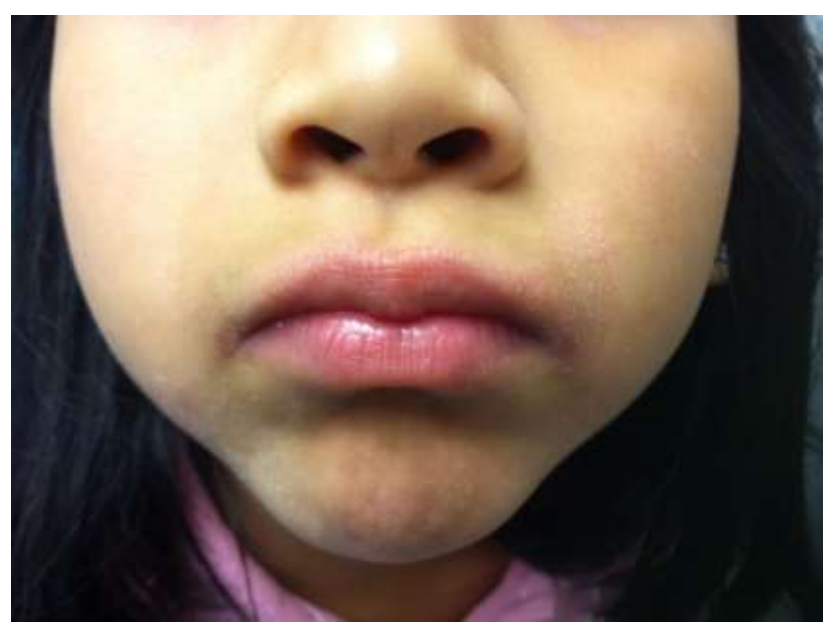

Figure 2: Perioral dermatitis

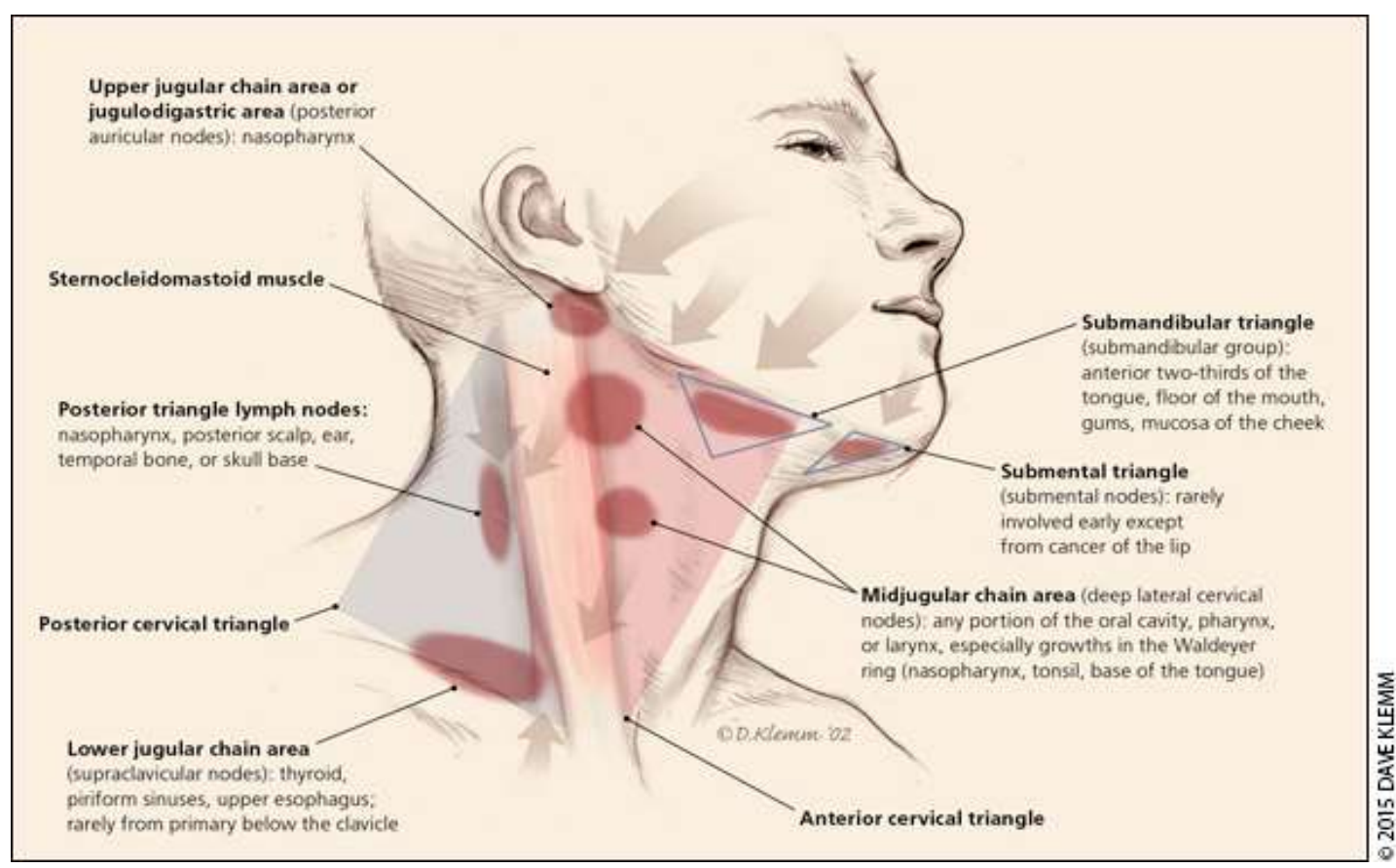

Figure 3: Common lymphatic drainage of the head and neck 


\section{References}

1. American College of Radiology. ACR Appropriateness Criteria. Neck mass/adenopathy.

2. Peters TR. (2000) Cervical Lymphadenopathy and Adenitis. Pediatrics in review (Elk Grove Village, Ill : Acad), Vol. 21, No. 12, p. 399-405

3. Zangwill KM. (2013) Cat scratch disease and other Bartonella infections. Adv Exp Med Biol. 764:159-166.

4. Hamilton DH, Zangwill KM, Hadler JL, Carter ML. (1995) Catscratch disease Connecticut, 1992-1993. J Infect Dis. 172: 1. 570-573.

5. Gioarcchini FM, Alicandri-Ciufelli M, Kaleci S, Magliulo G, Presutti L, Re M. (2015) Clincial presentation and treatment outcomes of thyroglossal duct cysts: a systematic review. Int $J$ Oral Maxillofac Surg. 44(1):119-26.
6. Srouji IA, Okpala N, Nilssen E, Birch S, Monnery P. (2004) Diagnostic cervical lymphadenectomy in children: a case for multidisciplinary assessment and formal management guidelines, Int J Pediatr Otorhi. 68 (5): 551-556.

7. Leung AK, Robson WL: (2004) Childhood cervical lymphadenopathy. J Pediatr Health Care 18: 3- 7.

8. Dickson PV, Davidoff AM. (2006) Malignant neoplasms of the head and neck. Semin Pediatr Surg, 15:92-98

9. Leung AK, Davies HD. (2009) Cervical lymphadenitis: etiology, diagnosis, and management. Curr Infect Dis Rep. 11(3):183-9.

10. Meier JD, Grimmer JF. (2014) Evaluation and management of neck masses in children. Am Fam Physician. 89:353-358

11. Chesney PJ: (1994) Cervical lymphadenopathy. Pediatr Rev, 15: 276-284.

12. Watt CJ, Hong HC. (2002) Dermacase. Lip Licker's Dermatitis. Can Fam Physician, 48:151.

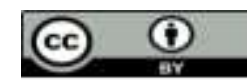

This work is licensed under Creative Commons Attribution 4.0 License

To Submit Your Article Click Here: Submit Manuscript

DOI: $10.31579 / 2690-8808 / 084$
Ready to submit your research? Choose Auctores and benefit from:

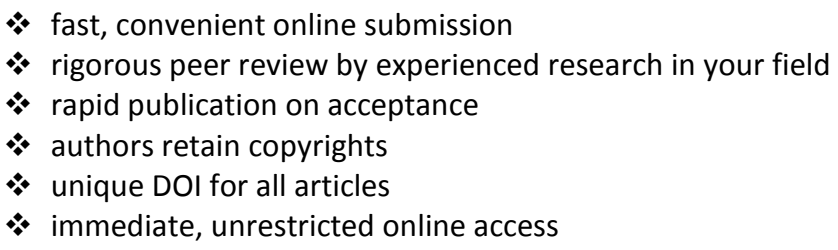

At Auctores, research is always in progress.

Learn more www.auctoresonline.org/journals/journal-of-clinical-casereports-and-studies 